\title{
Professional Service Utilisation among Patients with Severe Mental Disorders
}

\author{
Marie-Josée Fleury¹, Guy Grenier², Jean-Marie Bamvita² and Jean Caron
}

\begin{abstract}
Background: Generally, patients with serious mental disorders (SMD) are frequent users of services who generate high care-related costs. Current reforms aim to increase service integration and primary care for improved patient care and health-care efficiency. This article identifies and compares variables associated with the use by patients with SMD of services offered by psychiatrists, case managers, and general practitioners (GPs). It also compares frequent and infrequent service use.

Method: One hundred forty patients with SMD from five regions in Quebec, Canada, were interviewed on their use of services in the previous year. Patients were also required to complete a questionnaire on needs-assessment. In addition, data were collected from clinical records. Descriptive, bivariate, and multivariate analyses were conducted.

Results: Most patients used services from psychiatrists and case managers, but no more than half consulted GPs. Most patients were followed at least by two professionals, chiefly psychiatrists and case managers. Care access, continuity of care, and total help received were the most important variables associated with the different types of professional consultation. These variables were also associated with frequent use of professional service, as compared with infrequent service use. In all, enabling factors rather than need factors were the core predictors of frequency of service utilisation by patients with SMD.

Conclusion: This study reveals that health care system organisation and professional practice - rather than patient need profiles - are the core predictors of professional consultation by patients with SMD. The homogeneity of our study population, i.e. mainly users with schizophrenia, recently discharged from hospital, may partly account for these results. Our findings also underscored the limited involvement of GPs in this patient population's care. As comorbidity is often associated with serious mental disorders, closer follow-up by GPs is needed. Globally, more effort should be directed at increasing shared-care initiatives, which would enhance coordination among psychiatrists, GPs, and psychosocial teams (including case managers). Finally, there is a need to increase awareness among health care providers, especially GPs, of the level of care required by patients with disabling and serious mental disorders.
\end{abstract}

\section{Background}

The prevalence of mental disorders worldwide ranges from $4.3 \%$ to $26.4 \%$ per year; these conditions represent $12 \%$ of the disease burden [1]. Severe mental disorders (SMD, e.g. schizophrenia) are less prevalent (2-3\% of the population), but they account for close to half of total mental health care costs [2]. The burden of SMD has prompted countries to improve their mental health care system by strengthening community-based services and primary care for these patients. Essentially, these reforms

* Correspondence: flemar@douglas.mcgill.ca

1 Department of Psychiatry, McGill University, Researcher, Douglas Hospital Research Centre, 6875 LaSalle Blvd., Montreal, Quebec, H4H 1R3, Canada Full list of author information is available at the end of the article encourage general practitioners (GPs) and case managers (usually a nurse or social worker) to follow more patients with SMD in the community [1,3]. Primary care and community-based services are considered less stigmatising, more accessible, and no costlier than hospital-based care; in addition, they are often more greatly appreciated by patients [4-6]. Yet, hospitals and psychiatric care continue to occupy a central place in the mental health care system $[7,8]$. Most patients with SMD are still treated by psychiatrists [9]. However, most patients who live in the community are followed by case managers whose main function is to reduce hospital admission, increase use of community-based services, and enhance their patients' quality of life [10]. Finally, as chronic health problems are 
closely associated with SMD, a large proportion of these patients receive physical care as well as mental health aftercare from a GP [11]. In the United Kingdom, where primary care and specialised mental health services are closely integrated [12], up to $40 \%$ of patients with SMD rely mainly on a GP for their medical care and psychiatric medication [11,13]. Generally, however, patients with SMD, who are burdened with chronic disease and major functional disability, need substantial help from various resources on a long-term basis to meet their multiple biopsycho-social needs [14].

Patterns of mental health care service use have been investigated in many epidemiological studies; to date, however, very little research has focused on patients with SMD. Frequent users of psychiatric services (revolvingdoor patients) have received the most scrutiny [15-17]. While there is no unambiguous definition of 'frequent users' or clear demarcation between 'frequent' and 'infrequent' service users, certain socio-demographic and clinical characteristics associated with patients who make more frequent use of services have come to light [18]. These patients are generally male, young or middle-aged, and live alone. In addition, they lack social support and are often unemployed and homeless. Their main reported diagnoses are schizophrenia and other psychotic disorders, personality disorders, substance abuse, and chronic illness. Non-compliance with medication, numerous previous hospitalisations, and inadequate access to aftercare are also associated with frequent resource use, chiefly frequent readmission to hospital or psychiatric emergency rooms and longer length of in-patient stay, incurring above-average health care costs. Generally, frequent users are treated mainly by psychiatrists $[12,19,20]$. By comparison, patients with SMD followed by GPs are generally older, female, more educated, and live with a spouse or partner. They also receive more support from their families, have fewer symptoms, are more functional, and use relatively few mental health care services compared with patients treated by psychiatrists [12]. Generally, GPs offer care mainly to patients with mental disorders such as depression and anxiety and request help from psychiatrists and other psychosocial professionals for more complex conditions $[21,22]$

Some studies have also compared the profile of patients with SMD who use services provided by case managers with those who use more standard services [23]. Case manager patients reportedly receive more assistance, have fewer unmet needs, are more likely to stay in contact with service providers post hospital discharge, and express greater satisfaction with services [24] than patients who are not followed by case managers. Other studies have shown that patients with more frequent contact with case managers have more psychiatric symp- toms, worse psychosocial functioning, a poor social network, and reduced quality of life [23,25].

Despite the growing interest in user profiles among patients with SMD and alternatives to hospital-based care, we have found no study that looks at predictors of service-use frequency by patients with SMD involving the three major categories of professionals (psychiatrists, GPs, case managers). No previous study has also compared predictors of service utilisation of various frequent and infrequent users, taking into account concurrent consultation of one or more professionals. Since frequent users account for an estimated $20 \%$ to $50 \%$ of all psychiatric admissions [26], greater knowledge of their serviceuse patterns would contribute to efforts to improve service organisation. Given the aims of health care reforms, a clearer understanding of variables that enable or hinder service use by patients with SMD would be of great value.

The health care system in Quebec and Canada is an interesting context in which to study professional service utilisation by patients with SMD. In Canada, health care management is a provincial jurisdiction and has been regionalised over the past two decades. Under the Canada Health Act, all residents are entitled to free in-patient or out-patient care at the point of delivery. Patients receive treatment at publicly funded facilities or are seen by private specialists or GPs in the community who charge their provincial health plan for their services. Almost all psychiatrists practise in hospital settings; most GPs practise in group or solo private clinics. Case managers can work in hospitals or community health centres (known as CLSCs in Quebec). In addition, supervised housing resources and voluntary organisations such as self-help groups are also active health-care providers for patients with SMD. In Quebec, health care and social services are integrated. Several initiatives have been put forward to improve mental health care system integration, including shared care which aims to enhance service coordination among GPs, psychiatrists, and multidisciplinary mental health teams. However, many service providers still work alone, and waiting-time for access to psychiatrist expertise is very long $[27,28]$.

As in most epidemiological studies carried out to predict health care service utilisation, Andersen's behavioural model $[29,30]$ was used to frame our analysis. This model has the merit of encompassing individual and contextual dimensions. It classifies predictors of service use into three categories: predisposing, enabling, and need factors. Predisposing factors are individual characteristics that exist prior to the illness (e.g. socio-demographic profile and attitudes, values, and knowledge about services). Enabling factors refer to various features that influence care delivery and attitudes toward care; they encompass variables such as income, social support, and perception of care satisfaction and adequacy. Need fac- 
tors include the assessment of physical and mental health both by patients and professionals (e.g. individual's illness or impairment requiring service use).

This study is one of the first to examine predictors of professional consultation for patients with SMD using the Andersen's model. Its aim is to identify and compare variables associated with the use by patients with SMD of services offered by psychiatrists, general practitioners (GP), and case managers. The article also compares variables associated with frequent service use of one professional solely, and groups of two or three professionals respectively, with infrequent or no users (or frequent users of zero professionals). Frequent users are defined in this study as consulting psychiatrist or GP services, respectively, more than once every six months, or case manager services, more than once every two months. We hypothesised that for each type of professional, predictors of patient use frequency would be distinct. We also believe that hindering factors are more likely to be associated with frequent service use as compared with infrequent service use.

\section{Methods}

The study has a cross-sectional design and was conducted in Quebec (Canada). Patients were recruited in five areas in the province, representing urban, semiurban, and rural areas. Recruitment was carried out from December 2004 to June 2005. Inclusion conditions required that patients: (1) be aged 18 to 65 ; (2) be living in the community; (3) were hospitalised in the course of the previous year; and (4) were diagnosed with SMD according to ICD-9-CM diagnosis criteria 295 (Schizophrenia), 296 (Episodic Mood disorders, specifically bipolar disorders) or 297 (Delusional disorders). Based on these criteria, patients were selected from a list of 332 individuals whose names were provided by hospital archives in the participating areas. Following verification, 40 patients were excluded because they did not meet all of the abovelisted criteria. Another 68 were excluded as their case managers deemed them unfit for participation (extreme severity of disorder, language barriers). In addition, 84 subjects declined the offer to participate. The final sample consisted of 140 subjects out of 224 potential participants, for a response rate of $62.5 \%$.

Data collection was based on patient clinical records and the use of two instruments: the Camberwell Assessment of Needs (CAN) and a questionnaire on serviceutilisation patterns. Both instruments were administered by research assistants with a professional clinical background who received special training as part of the study. Patients were interviewed at home or elsewhere at their convenience and were offered modest financial compensation to cover travel expenses and their time. The research was approved by the relevant ethics boards at hospitals and community-based agencies. Each participant was required to sign a consent form after receiving a complete and clear description of the study.

\section{Measurement instruments and predictors}

The CAN is one of the most commonly used instruments for comprehensive needs-assessment in mental health services. Developed by the Health Service Research Department of the Institute of Psychiatry in London, the CAN has been widely studied [31-33]. Its reliability has been demonstrated both for population of different languages and cultures [34-38]. The French version has been validated with long-term hospitalized patients in Quebec, Canada [39]. In addition to assessing patient needs, the CAN may also be used to gauge: help provided by relatives or services; perceived need for help from services; and adequacy of, and satisfaction with, help provided. The CAN questionnaire covers 22 clinical and psychosocial domains, grouped into five needs categories: (i) basic (accommodation, food, daytime activities); (ii) health (physical health, psychotic symptoms, psychological distress, safety to self, safety to others, alcohol use, drug use); (iii) functioning (self-care, looking after the home, child care, basic education, money); (iv) social (company, intimate relationships, sexual expression); and (v) information and utilities (information on the illness and its treatment, transport, telephone, benefits). For each of the 22 domains, patients indicated perceived problems on a three-point scale (no problem $=0$, moderate problem $=1$, serious problem $=2$ ). If a moderate or serious problem was reported, patients were asked questions on: the level of help received from relatives; the level of help needed and received from services (none $=0$, low $=1$, moderate $=$ 2 , high $=3$ ); and, finally, whether they received the right type (adequate $=1$; not adequate $=0$ ) and the right amount of help (satisfied $=1$; not satisfied $=0$ ). In every section, patients are permitted to answer, 'I don't know'.

The questionnaire on service utilisation patterns was adapted from the Statistics Canada Canadian Community Health Survey (CCHS 1.2) for patients with SMD [40]. In support of efforts to adapt the questionnaire, a literature review was conducted using Ovid Medline and PubMed research database content from 1996 onward on service-use patterns, care continuity, and shared-care mental health models. The validity of the questionnaire's content was assessed by twelve experts in the field and pre-tested with ten patients not included in the sample. The final version contained 48 items divided into five sections: patterns of service use; consultations with psychiatrists; with GPs; and with case managers, and relationships with family members. Generally, the questionnaire featured open-ended or multiple-choice questions, but also included a few five-point Likert Scale questions. 
To gauge predisposing factors, both patient clinical records (age, gender, marital status, and education) and the questionnaire on service utilisation patterns (importance of service accessibility in terms of opening hours, waiting time to getting help, and geographic availability, and number of health and social resources familiar to the patient) were used (Figure 1). Data on potential enabling factors were collected from patient clinical records (work, income sources, housing type and location, compliance with medication) and from the service-use questionnaire (presence or absence of contact with relatives; duration of follow-up with psychiatrist, GP, or case manager; and satisfaction with service accessibility in terms of opening hours, waiting time to access help, and geographic accessibility, quantity and diversity of available services, and ease of accessing a psychiatrist, GP, and case manager). Enabling factors were also gauged using the CAN questionnaire: amount of help for global needs and need categories from relatives or from services, and proportion of needs receiving adequate help. Finally, need factors were extracted from the patient clinical records (first and second diagnoses, suicide attempts, history of psychiatric disorders in the family, alcoholism or drug addiction, violence, and a criminal record) and from the CAN (number of: needs, serious needs, and health needs; and percentage of: serious needs out of total needs and health needs out of total needs).

\section{Data analyses}

All variables included in predisposing, enabling, and need factors were used as independent variables. To identify independent variables associated with the frequency of patient consultation with psychiatrists, GPs, and case managers, respectively, multiple linear regressions were conducted on each of these dependent variables. Fre-

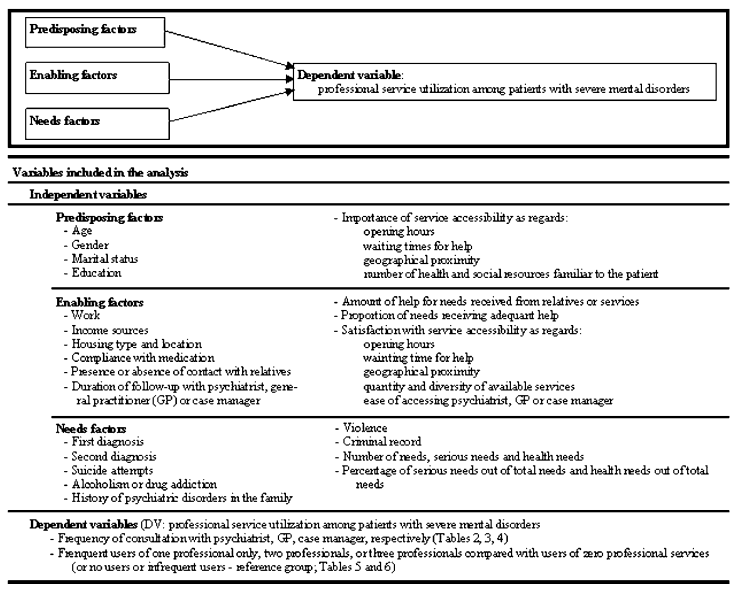

Figure 1 The Andersen behavioural Model of Health Service Utilisation. quency of consultation was a continuous variable related to each professional and was measured based on service use in the past 12 months. Patients could answer that they had visited psychiatrists, GPs or case managers zero to several times, on a weekly, monthly or yearly basis. Multinomial logistic regression was used to compare variables associated with infrequent and frequent professional service use. The sample was divided into four groups consisting of frequent professional service users of: all three categories of professionals concurrently; two categories; one category; or none of the categories of professionals (i.e. infrequent professional service users or no users). The line separating frequent from infrequent professional service users was set based on the frequency of consultation per each professional as reported in statistics collected as part of mental health care reforms in Quebec [41]. Frequent users of psychiatrist or GP services were found to consult these professionals, respectively, more than once every six months. Frequent users of case manager services were found to consult these professionals more than once every two months. This cut-off line also represents the median of use-frequency levels (if patients are distributed into equal subcategories).

Both multiple linear and logistic models were preceded by univariate and bivariate analyses. Univariate analysis included verification of normality distribution and calculation of mean values for continuous variables and of frequency distribution for categorical variables. Linear bivariate analyses consisted of testing significant associations among each of the three continuous dependent variables and all independent variables $(P \leq 0.10)$. All independent variables found, in the preceding step, to be significantly associated were used to build multiple linear regression models using the backward stepwise LR technique $(\mathrm{P} \leq 0.05)$. The final models were assessed as to goodness-of-fit and proportion of variance explained. To build the multinomial logistic regression model, independent variables significantly associated with the four-category dependent variable in bivariate analyses were used $(\mathrm{P} \leq 0.10)$. The improvement of the multiple model as regards goodness-of-fit was achieved using the Likelihood Ratio test: variables yielding Chi-square test with non-significant $P$ value $(P>0.05)$ were excluded step by step. Adjusted odds ratios (ExpB) were presented that compared frequent users of 1,2 and 3 professionals with infrequent or non users. Finally, a Nagelkerke Pseudo RSquare was computed to estimate the proportion of variance explained.

\section{Results}

\section{Description of the sample}

Predisposing, enabling, and need factors and service utilisation characteristics are displayed in Table 1. The majority of participants ( 86 of $140,61 \%$ ) were males, with 
Table 1: Predisposing, enabling and need factors and service utilisation characteristics $(n=140)$

\begin{tabular}{|c|c|c|c|c|c|}
\hline & & & & Frequency & Percent \\
\hline $\begin{array}{l}\text { Predisposing } \\
\text { factors }\end{array}$ & & $\begin{array}{l}\text { Importance attributed to } \\
\text { service accessibility in terms of } \\
\text { opening hours }\end{array}$ & Very important & 33 & 23.6 \\
\hline \multirow[t]{14}{*}{ Enabling factors } & Amount of help from services for (mean, SD): & functioning needs & & 2.4 & 1.2 \\
\hline & & information and utility needs & & 2.0 & 0.9 \\
\hline & & social needs & & 1.9 & 0.9 \\
\hline & Amount of help from relatives for: & global needs & & 5.6 & 3.2 \\
\hline & & social needs & & 1.8 & 1.09 \\
\hline & Duration of follow-up (in years) by (mean, SD): & psychiatrist & & 3.01 & 1.42 \\
\hline & & general practitioner (GP) & & 1.78 & 2.04 \\
\hline & & case manager & & 2.12 & 1.45 \\
\hline & Satisfaction with regard to: & geographic accessibility & Very satisfied & 34 & 24.3 \\
\hline & & diversified service accessibility & Very satisfied & 28 & 20.0 \\
\hline & & waiting time to receive help & Very satisfied & 27 & 19.3 \\
\hline & Satisfaction with ease of accessing a: & GP & Very satisfied & 22 & 15.7 \\
\hline & & psychiatrist & Very satisfied & 27 & 19.3 \\
\hline & & case manager & Very satisfied & 29 & 20.7 \\
\hline \multirow[t]{15}{*}{ Need factors } & Number of & global needs (mean, SD) & & 5.9 & 3.6 \\
\hline & & serious needs (mean, SD) & & 1.9 & 2.1 \\
\hline & & health needs (mean, SD) & & 2.0 & 1.4 \\
\hline & Diagnoses: & Main diagnosis & $\begin{array}{l}\text { Schizoaffective } \\
\text { disorders }\end{array}$ & 59 & 42.1 \\
\hline & & & $\begin{array}{l}\text { Paranoid } \\
\text { schizophrenia }\end{array}$ & 49 & 35.0 \\
\hline & & & $\begin{array}{l}\text { Others } \\
\text { schizophrenic } \\
\text { disorders }\end{array}$ & 25 & 17.9 \\
\hline & & & $\begin{array}{l}\text { Delusional } \\
\text { disorders }\end{array}$ & 5 & 3.6 \\
\hline & & & $\begin{array}{l}\text { Bipolar } \\
\text { disorders }\end{array}$ & 2 & 1.4 \\
\hline & & Second diagnosis & $\begin{array}{l}\text { Personality } \\
\text { disorders }\end{array}$ & 29 & 20.7 \\
\hline & & & $\begin{array}{l}\text { Bipolar } \\
\text { disorders }\end{array}$ & 5 & 3.6 \\
\hline & & & Autism & 1 & 0.7 \\
\hline & History of suicide attempts (yes/no) & & & 42 & 30.0 \\
\hline & Number of suicide attempts (mean, SD) & & & 0.42 & 0.98 \\
\hline & History of violence (yes/no) & & & 38 & 27.0 \\
\hline & Psychiatric disorders in the family (yes/no) & & & 63 & 45.0 \\
\hline
\end{tabular}




\begin{tabular}{llll}
\hline $\begin{array}{l}\text { Service } \\
\text { utilisation }\end{array}$ & $\begin{array}{l}\text { Patient distribution according to number of professionals frequently consulted } \\
\text { ('frequent users') }\end{array}$ & 0 & 14 \\
& & 1 & 38.0 \\
& & 2 & 67 \\
& 3 & 47.9 & 14 \\
\hline
\end{tabular}

a mean age of 47 years $(S D=12)$. The sample was compared to non-responding patients for gender distribution and age, which yielded non-significant results (age: $\mathrm{t}=$ 1.489; $\mathrm{df}=222 ; \mathrm{P}=0.138$ ); (gender: Pearson $\mathrm{X}^{2}=0.011 ; \mathrm{df}$ $=1 ; \mathrm{P}=1.000)$. The sample was also compared with all Quebec hospitalised patients for the same year and diagnoses [42], for age $(\mathrm{d} f=1611 ; \mathrm{P}=0.222)$ and gender distribution $\left(X^{2}=6.331 ; \mathrm{d} f=1 ; \mathrm{P}=0.012\right)$. No difference between our sample and the Quebec patient population was found with regard to age. A difference was found for gender distribution, with an overrepresentation of men in our sample.

Most study participants had completed secondary school ( $\mathrm{n}=106,76 \%)$, and some had a university degree ( $\mathrm{n}=17,13 \%)$. The vast majority were unmarried $(\mathrm{n}=128$, $91 \%)$. Most lived in urban areas $(\mathrm{n}=84,60 \%)$. The predominant source of income was social welfare $(n=94$, $70 \%)$, though some respondents were employed $(n=15$, $11 \%)$. As for housing, most participants lived in their own apartment ( $\mathrm{n}=84,60 \%)$; others in supervised facilities ( $\mathrm{n}$ $=56,40 \%)$. Service-utilisation distributions revealed a greater use of hospital-based services $(n=122,87 \%)$ than of primary care services $(n=113,81 \%)$. Almost all participants reported being followed by a psychiatrist $(\mathrm{n}=130$, $93 \%)$ and half by a GP $(n=70,50 \%)$. Finally, $84 \%$ of participants reported being followed by a case manager $(\mathrm{n}=$ 117).

\section{Modelling frequency of professional service use}

Overall, 101 patients with SMD (72\%) reported visiting psychiatrists at least once in six months, while the remaining 39 participants (28\%) saw them less often or did not consult them. As for GP consultation, 43 patients with SMD (31\%) indicated seeing them at least once every 6 months, while the remaining 97 participants (69\%) reported visiting them less often or did not consult them. Finally, a total of 91 participants (65\%) mentioned visiting case managers at least once per two months, while the remaining 49 (35\%) saw them less often or did not use their services. Variables associated with the frequency of psychiatrist, GP, and case manager consultations are displayed, respectively, in Tables 2, 3 and 4. In bivariate analyses, 11 independent variables for psychiatrists, 17 for GPs, and 8 for case managers were significantly associated with the frequency of consultation of these professionals. Variables included in the final regression linear models explain respectively $50 \%, 61 \%$ and $18 \%$ of the total variation for psychiatrist, GP, and case manager consultation. In the final model, there are three variables associated with psychiatrist consultation: satisfaction with regard to access to a psychiatrist; access to diversified services; and number of suicide attempts. Four variables associated with GP consultation were identified: satisfaction with regard to access to a GP; duration of patient follow-up by GPs; and amount of help from relatives for social and global needs. Finally, there were two variables associated with case manager consultation: duration of patient follow-up by the case manager; and amount of help from services for information and utility needs.

\section{Modelling frequent professional service users as compared with infrequent users}

Out of the four user groups, frequent users of two categories of professionals were the largest group, corresponding to $48 \%$ of the sample ( $n=67$ patients). Of this group, $77 \%(\mathrm{n}=52)$ were followed by a psychiatrist and case manager, $15 \%(\mathrm{n}=10)$ by a GP and case manager, and $8 \%$ $(\mathrm{n}=5)$ by a psychiatrist and GP. The second-largest user group consisted of frequent users of only one category of professionals $(27 \%, \mathrm{n}=38)$, including psychiatrists at $63 \%$ $(\mathrm{n}=24)$, case managers at $24 \%(\mathrm{n}=9)$, and GPs at $13 \%(\mathrm{n}$ $=5$ ). Patients reporting high frequency consultation of all three categories of professionals (the third group in importance out of the four user groups) represented 15\% $(\mathrm{n}=21)$. Finally, the last group, i.e. users with few consultations or who did not consult professionals, accounted for $10 \%$ of the sample $(n=14)$.

Table 5 presents variables associated with these four user groups in bivariate analyses. The multinomial logistic regression model is displayed in Table 6 (users with a low consultation rate are the control group). The independent variables included in the final model explain $45 \%$ of the total variance (Nagelkerke Pseudo R-Square). This model highlights the fact that the duration of patient follow-up by case managers increases the likelihood of more frequent visits with a larger number of professionals. The probability of patients' being frequent users of more categories of professionals also rose with their satisfaction regarding the ease of accessing GPs. Satisfaction regard- 
Table 2: Variables associated with the frequency of psychiatrist consultations

\begin{tabular}{|c|c|c|}
\hline & $\begin{array}{r}\text { Bivariate analyses Standardized Beta ( } \mathbf{P} \\
\text { value) }\end{array}$ & $\begin{array}{c}\text { Multiple linear regression Standardized } \\
\text { Beta }(95 \% \mathrm{Cl})\end{array}$ \\
\hline \multicolumn{3}{|l|}{ Enabling factors } \\
\hline $\begin{array}{l}\text { Housing situation (supervised vs } \\
\text { autonomous) }\end{array}$ & $0.157(0.097)$ & \\
\hline $\begin{array}{l}\text { Amount of help from services for } \\
\text { social needs }\end{array}$ & $0.274(0.024)$ & \\
\hline Duration of follow-up by psychiatrist & $0.495(<0.001)$ & \\
\hline $\begin{array}{l}\text { Duration of follow-up by case } \\
\text { manager }\end{array}$ & $0.190(0.043)$ & \\
\hline $\begin{array}{l}\text { Satisfaction with regard to diversified } \\
\text { service accessibility }\end{array}$ & $-0.200(0.037)$ & $-0.338(-0.612 ; 0.184)$ \\
\hline $\begin{array}{l}\text { Satisfaction as regard waiting time to } \\
\text { getting help }\end{array}$ & $0.188(0.047)$ & \\
\hline $\begin{array}{l}\text { Satisfaction as regard ease of } \\
\text { accessing psychiatrist }\end{array}$ & $0.583(<0.001)$ & $0.537(0.316 ; 0.630)$ \\
\hline \multicolumn{3}{|l|}{ Need factors } \\
\hline $\begin{array}{l}\text { Schizoaffective disorders as first } \\
\text { diagnosis }\end{array}$ & $0.260(0.005)$ & \\
\hline $\begin{array}{l}\text { Personality disorders as a second } \\
\text { diagnosis }\end{array}$ & $0.326(<0.001)$ & \\
\hline History of suicide attempts & $0.168(0.075)$ & \\
\hline \multirow[t]{2}{*}{ Number of suicide attempts } & $0.179(0.058)$ & $0.206(0.029 ; 0.483)$ \\
\hline & & $\begin{array}{l}F=20,935 ; P<0,001 \\
R 2=49,9 \%\end{array}$ \\
\hline
\end{tabular}

ing the ease of accessing psychiatrists was also found to be significantly associated with frequent users, primarily of one category of professionals only, and secondarily, two categories of professionals.

\section{Discussion}

The task of identifying and comparing predictors of service use by category of professionals (psychiatrists, GPs, case managers) contributes to efforts to promote alternatives to hospital-based services [3], which are central to current health care reforms. Very few studies have explored patterns of service use by patients with SMD $[43,44]$. Our study is one of the first to observe these patients using Andersen's behavioural model. Patients with SMD usually present with characteristics that favour close follow-up by physicians and psychosocial professionals, such as case managers [30]. Since one sample inclusion criterion was that patients must have been hospitalised in the past twelve months, frequent users accounted for the large majority in our sample. Frequent users are a leading priority in current health care reforms as they are highly vulnerable, face major stigmatisation, and generate considerable health care costs $[18,26]$.

Contrary to the literature focusing on the use of Andersen's model in the general population [40], in our regression models, seeking mental health care services from psychiatrists and GPs explained an acceptable level - 50\% and $61 \%$, respectively - of the variance. The case manager model was also acceptable, explaining $18 \%$ of the variance. In opposition to much of the literature [45-47], of the nine variables associated with service use for the three professional categories in our final regression linear models, only one was related with the need-factor category (i.e. number of suicide attempts). All other predictors were enabling factors. These results are coherent with findings reported by Lemming and Calsyn [30] who also studied utilisation of services for patients with SMD. As the latter are quite a homogenous population - in our sample, almost all had schizophrenia - it is not surprising that the need-factor category is not closely associated with the frequency of professional consultation. Need factors are usually the prime predictors of service use in 
Table 3: Variables associated with the frequency of general practitioner (GP) consultations

\begin{tabular}{|c|c|c|}
\hline & $\begin{array}{c}\text { Bivariate analyses Standardised Beta } \\
\text { (P value) }\end{array}$ & $\begin{array}{l}\text { Multiple linear regression } \\
\text { Standardised Beta }(95 \% \mathrm{CI})\end{array}$ \\
\hline \multicolumn{3}{|l|}{ Predisposing factors } \\
\hline Age & $0.160(0.068)$ & \\
\hline Gender $($ male $=1)$ & $0.246(0.005)$ & \\
\hline Marital status & $0.319(<0.001)$ & \\
\hline $\begin{array}{l}\text { Importance attributed to service accessibility in terms of } \\
\text { opening hours }\end{array}$ & $0.295(0.001)$ & \\
\hline \multicolumn{3}{|l|}{ Enabling factors } \\
\hline Housing situation (supervised vs autonomous) & $-0.173(0.049)$ & \\
\hline Territory (urban vs semi-urban/rural) & $-0.263(0.002)$ & \\
\hline Amount of help from relatives for social needs & $0.235(0.033)$ & $0.166(0.012 ; 0.622)$ \\
\hline Amount of help from relatives for global needs & $0.160(0.068)$ & $0.161(0.006 ; 0.183)$ \\
\hline Duration of follow-up by GP & $0.692(<0.001)$ & $0.351(0.069 ; 0.470)$ \\
\hline Duration of follow-up by case manager & $0.261(0.003)$ & \\
\hline Satisfaction with regard to geographic accessibility & $0.152(0.089)$ & \\
\hline Satisfaction with regard to waiting time to receive help & $0.179(0.040)$ & \\
\hline Satisfaction with regard to ease of accessing a GP & $0.738(<0.001)$ & $0.425(0.124 ; 0.516)$ \\
\hline \multicolumn{3}{|l|}{ Need factors } \\
\hline Number of health needs & $0.178(0.042)$ & \\
\hline History of suicide attempts & $0.186(0.034)$ & \\
\hline Number of suicide attempts & $0.182(0.037)$ & \\
\hline \multirow[t]{2}{*}{ Psychiatric disorders in the family } & $0.154(0.095)$ & \\
\hline & & $\begin{array}{c}\mathrm{F}=26.887 ; \mathrm{P}<0.001 \\
\mathrm{R} 2=61.3 \%\end{array}$ \\
\hline
\end{tabular}

epidemiological studies involving global populations [4547].

The only need variable in the multivariate analyses, i.e. number of suicide attempts, was associated with more psychiatrist consultations. Suicide is the leading cause of premature death among patients with schizophrenia [48]. Suicide and suicide attempts occur at a significantly greater rate in persons with schizophrenia than in the general population [49]. It is estimated that $10 \%$ to $13 \%$ of individuals with schizophrenia commit suicide, and $20 \%$ to $40 \%$ make suicide attempts [50]. Moreover, recent discharge from hospital (as in our sample) is associated with more suicide and suicide attempts [49,51]. These highrisk patients require greater specialised care, especially from psychiatrists.

Unexpectedly, there was scant difference between variables associated with the frequency of consultation among any of the three professional categories. The eight other predictors of one or another category of professionals involved either the amount of help received (i.e. from relatives for global and social needs or from services for information and utility needs), care access or continuity of care. In the literature [52-54], adequate follow-up of patients with chronic or serious disorders has been found to be closely associated with an extensive range of services received, along with care accessibility and continuity. The positive association between GP consultation and the amount of help received from relatives for global and social needs may signify that patients who consult GPs with greater frequency enjoy a stronger family network. This network may complement services offered by GPs, especially in more intimate areas of a patient's life, involving need domains with which professionals may be less comfortable (such as intimate relationships and sexual expression). A family network may also encourage 


\begin{tabular}{|c|c|c|}
\hline & $\begin{array}{c}\text { Bivariate analyses Standardized Beta } \\
\text { (P value) }\end{array}$ & $\begin{array}{c}\text { Multiple linear regression Standardized } \\
\text { Beta }(95 \% \mathrm{Cl})\end{array}$ \\
\hline \multicolumn{3}{|l|}{ Predisposing factors } \\
\hline Gender $($ male $=1)$ & $0.161(0.058)$ & \\
\hline Marital status & $0.222(0.008)$ & \\
\hline \multicolumn{3}{|l|}{ Enabling factors } \\
\hline Territory (urban vs semi-urban/rural) & $-0.206(0,015)$ & \\
\hline $\begin{array}{l}\text { Amount of help from services for information } \\
\text { and utility needs }\end{array}$ & $0.220(0.060)$ & $0.186(0.068 ; 0.794)$ \\
\hline Duration of follow-up by GP & $0.142(0.093)$ & \\
\hline Duration of follow-up by case manager & $0.441(<0.001)$ & $0.356(0.160 ; 0.684)$ \\
\hline $\begin{array}{l}\text { Satisfaction with regard to diversified service } \\
\text { accessibility }\end{array}$ & $0.197(0.022)$ & \\
\hline \multirow[t]{2}{*}{$\begin{array}{l}\text { Satisfaction with ease of accessing } \\
\text { psychiatrist }\end{array}$} & $0.160(0.059)$ & \\
\hline & & $\begin{array}{c}F=7,270 \\
P=0,001 \\
R 2=17,6 \%\end{array}$ \\
\hline
\end{tabular}

patients to consult GPs to maintain their level of health [55].

Help provided in the information and utility need category is closely associated with case manager role (who provide information on the illness and its treatment and transport-related issues). The more frequently these professionals are consulted, the greater the amount of help received, especially in this need category $[56,57]$.

In Quebec and Canada, physician care can be difficult to access. It is worth mentioning that the Canadian health care system no longer ranks among the best in the world, due primarily to long waiting times to consult GPs or specialists [1]. An estimated $25 \%$ of the population in Quebec is without a GP; therefore, walk-in clinics are the sole health care solution for many people [58]. In our study, satisfaction with ease of access to psychiatrists and GPs was closely associated with more patient consultations. Nevertheless, the greater is the importance given to the frequency of psychiatrist consultation, the lower is patient satisfaction with access to diversified services. Patients seemed either to be 'stuck' with a particular psychiatrist when there was access to them or they consulted a psychiatrist because alternatives were scarce. When there is a shortage of GPs (as is the case currently in Quebec), the likelihood of patients with SMD being transferred to psychiatrists rises since these patients are more challenging and require more frequent care [59]. An alternative hypothesis is that patients may be satisfied with psychiatrist care alone and do not need other types of services. Finally, longitudinal continuity, defined as sustained follow-up over time, is a core component of global care and a major driver of service utilisation for patients with considerable needs, such as individuals with SMD [60-62].

Almost half of the patients in our study were reportedly frequent users of at least two categories of professionals: psychiatrists and case managers. Patients with SMD, especially with schizophrenia and recently hospitalised, usually need specialised care and close professional follow-up for their bio-psycho-social problems [63]. Generally, psychiatrists also recommend that case managers follow patients with major needs [64]. Only a minority of patients (23\%) consulted both psychiatrists and GPs. In Quebec, these professionals practice primarily in silo, as shared care (one of the aims of current reforms) is still relatively undeveloped [59]. As a result, GPs are the professionals whom patients with SMD consult least often, probably due to the access problems mentioned above, competing demands from other patients, and insufficient training among GPs in mental health care, and development of shared care [65]. Stigmatisation of patients with SMD by GPs has also been reported as a hindering factor (e.g. GPs' fear of patient crisis and psychotic disorders) [66].

Both service accessibility and longitudinal continuity appear to be core predictors of frequent use of profes- 
Table 5: Variables associated with the number of frequently used professionals: bivariate multinomial regression $(n=140)$

\begin{tabular}{|c|c|c|c|c|c|c|c|c|c|}
\hline & \multicolumn{3}{|c|}{ Frequent users of 1 professional $(n=38)$} & \multicolumn{3}{|c|}{ Frequent users of 2 professionals $(n=67)$} & \multicolumn{3}{|c|}{ Frequent users of 3 professionals $(n=21)$} \\
\hline & B & Sig. & $\operatorname{Exp}(B)$ & B & Sig. & $\operatorname{Exp}(B)$ & B & Sig. & $\operatorname{Exp}(B)$ \\
\hline \multicolumn{10}{|l|}{ Enabling factors } \\
\hline $\begin{array}{l}\text { Amount of help from services for } \\
\text { functioning needs }\end{array}$ & 0.024 & 0.941 & 1.024 & -0.194 & 0.526 & 0.824 & 0.63 & 0.1 & 1.878 \\
\hline $\begin{array}{l}\text { Amount of help from services for } \\
\text { information and utility needs }\end{array}$ & 1.837 & 0.096 & 6.279 & 1.889 & 0.083 & 6.616 & 2.445 & 0.031 & 11.534 \\
\hline $\begin{array}{l}\text { Duration of follow-up by general } \\
\text { practitioner (GP) }\end{array}$ & 0.032 & 0.851 & 1.032 & 0.099 & 0.536 & 1.104 & 0.478 & 0.01 & 1.612 \\
\hline $\begin{array}{l}\text { Duration of follow-up by case } \\
\text { manager }\end{array}$ & 0.063 & 0.789 & 1.065 & 0.4 & 0.072 & 1.492 & 0.512 & 0.047 & 1.668 \\
\hline $\begin{array}{l}\text { Satisfaction with regard to waiting } \\
\text { time to receive help }\end{array}$ & 0.045 & 0.844 & 1.047 & 0.277 & 0.22 & 1.319 & 0.671 & 0.043 & 1.957 \\
\hline $\begin{array}{l}\text { Satisfaction with ease of accessing a } \\
\text { GP }\end{array}$ & -0.038 & 0.819 & 0.963 & 0.106 & 0.486 & 1.112 & 0.725 & 0.001 & 2.064 \\
\hline $\begin{array}{l}\text { Satisfaction with ease of accessing a } \\
\text { psychiatrist }\end{array}$ & 0.308 & 0.093 & 1.361 & 0.466 & 0.009 & 1.593 & 0.536 & 0.018 & 1.708 \\
\hline
\end{tabular}

\section{Need factors}

$-1.034$

0.123

0.356

$-1.044$

0.091

0.352

0.192

0.782

1.212 
Table 6: Variables independently associated with the number of frequently used professionals: multiple multinomial regression

\begin{tabular}{|c|c|c|c|c|c|c|c|c|c|}
\hline & \multicolumn{3}{|c|}{ Frequent users of 1 professional $(n=38)$} & \multicolumn{3}{|c|}{ Frequent users of 2 professionals $(n=67)$} & \multicolumn{3}{|c|}{ Frequent users of 3 professionals $(n=21)$} \\
\hline & B & Sig. & $\operatorname{Exp}(B)$ & B & Sig. & $\operatorname{Exp}(B)$ & B & Sig. & $\operatorname{Exp}(B)$ \\
\hline \multicolumn{10}{|l|}{ Enabling factors } \\
\hline $\begin{array}{l}\text { Amount of help from services for functioning } \\
\text { needs }\end{array}$ & 0.059 & 0.889 & 1.061 & -0.267 & 0.511 & 0.765 & 0.56 & 0.268 & 1.75 \\
\hline Duration of follow-up by case manager & 0.837 & 0.056 & 2.309 & 0.96 & 0.025 & 2.613 & 1.252 & 0.01 & 3.498 \\
\hline $\begin{array}{l}\text { Satisfaction with ease of accessing a general } \\
\text { practitioner }\end{array}$ & 0.475 & 0.167 & 1.608 & 0.646 & 0.051 & 1.908 & 1.208 & 0.001 & 3.346 \\
\hline $\begin{array}{l}\text { Satisfaction with ease of accessing a } \\
\text { psychiatrist }\end{array}$ & 0.703 & 0.024 & 2.02 & 0.594 & 0.042 & 1.811 & 0.528 & 0.146 & 1.696 \\
\hline
\end{tabular}

Nagelkerke Pseudo R-Square: 0.451

Likelihood Ratio Tests: Chi-Square: 45.934; P $<0.001$

Reference group in the dependent variable: frequent users of zero professionals $(n=14)$ 
sional health care services, as compared to no or infrequent use in our multinomial regression model. In our findings, the higher were patient satisfaction with access to GPs and to the duration of case manager follow-up, the greater was the number of professionals consulted. This first finding may be due to the shortage of GPs. Recent studies $[28,59]$ have also suggested that GPs tend to transfer patients with mental disorders to specialists, but that collaborative care tends to reverse this trend. In our sample, only $50 \%$ of patients had access to GPs who did not necessarily provide continuous care to these patients. The literature on medical homes [67] has emphasised the importance for chronic care patients of having a regular primary care provider, especially a GP involved in care coordination. As for case managers, they generally enable service use and continued contact with service providers following patient discharge from hospital. As for longitudinal continuity, we have already reported its importance as a core component of care quality and driver for service use by patients with SMD [61].

Satisfaction with access to psychiatrists was primarily associated with patients' consulting a single category of professionals and secondarily with two categories of professionals. This finding supports our hypothesis that patients' satisfaction with services provided by psychiatrists reduces their need to consult other providers, such as GPs or case managers. In the great majority of cases where patients were followed by one professional or by two, the professional was or included a psychiatrist. This situation, however, is inconsistent with current trends and is not cost-effective. It also points to the need to raise awareness among the public and health care professionals of the importance of strengthening primary care and shared-care initiatives, which have been shown to provide effective service to patients with chronic disabilities [68]. Finally, as was the case for our multivariate linear analyses, the multinomial model did not corroborate our second hypothesis that hindering factors are more associated with frequent service users as compared with infrequent service users. We believed that a greater number of patient health needs would be associated with a greater volume of GP consultation, but this was not the case.

\section{Strengths and limitations}

The study is of value as it is one of the few that apply Andersen's comprehensive behavioural model to the use of professional health care services by patients with SMD. However, it includes certain limitations that are worth noting. It is a cross-sectional study; a longitudinal study would have allowed us to isolate associations among the different variables more effectively. As our cohort consisted almost exclusively of patients with schizophrenia, we cannot claim that our results are representative of the general population or even of a more diverse population of patients with SMD. Moreover, frequent users constitute the majority in our sample. Identifying predictors of professional consultation for this group is a priority considering the high costs of treating patients with SMD and the stigmatisation that they face. In addition, patients from rural areas or more remote regions (distant from university-affiliated or urban centres where psychiatrists are concentrated) were underrepresented in our sample. Patients who more frequently used psychiatrist services are primarily located in urban settings [69,70]. Compared with the Quebec hospitalised population with SMD, men were also overrepresented in our sample. Finally, the threshold employed to distinguish frequent users from infrequent users was not based on a strong consensus, since the literature provides little in the way of a definition of 'frequent' service users with SMD.

\section{Conclusion}

Contrary to what the literature suggests, our findings are that health care system organisation and professional practice have a greater impact on patient consultation of professional services than do patient need profiles. This finding may be due at least in part to the homogeneity of our study population (primarily frequent users with schizophrenia, recently discharged from hospital). Uncovering system inefficiency with regard to access and care continuity is a major issue in caring for individuals with SMD. GPs prove to be an underutilised resource. As SMD is often associated with comorbidity, such as physical (e.g. diabetes, obesity and hypertension) and substance abuse problems, it is crucial that patients with SMD be followed by GPs. Individuals with SMD should have the same access to care as the general population and receive services that are not stigmatising. Greater effort should be directed at increasing shared-care initiatives, favouring improved coordination among psychiatrists, GPs, and case managers. Generally, good care access, care continuity, and diversified services are strong predictors of quality of care for chronic and seriously disabled patients. While it is true that the province of Quebec provides fairly accessible public health care and is in the midst of bringing about major reforms to enhance integration and primary care, more effort is needed to implement organisational change and reduce stigmatisation for patients with SMD. Such developments would also be welcome in other countries, especially where private health care is more prevalent, as they would raise awareness of the need for adequate care access and care continuity for persons with serious and disabling disorders.

\section{Abbreviations}

CAN: Camberwell Assessment of Need; CLSC: Community Local Service centre; GP: General practitioner; SMD: Severe mental disorders. 


\section{Competing interests}

The authors declare that they have no competing interests.

\section{Authors' contributions}

MJF designed the study. JMB made the statistic analyses with the help of JC. MJF and GG wrote the article. All authors have read and approved the final manuscript.

\section{Acknowledgements}

The study was funded by the Canadian Institute of Health Research (CIHR). We would like to thank this grant agency, all the patients who participated in the research, and Youcef Ouadahi, who coordinated the study. We would also like to thank Norbert Schmitz who provided valuable assistance in the drafting of this article.

\section{Author Details}

1Department of Psychiatry, McGill University, Researcher, Douglas Hospital Research Centre, 6875 LaSalle Blvd., Montreal, Quebec, H4H 1R3, Canada and 2Douglas Hospital Research Centre, Montreal, Quebec, H4H 1R3, Canada

Received: 3 August 2009 Accepted: 27 May 2010

Published: 27 May 2010

\section{References}

1. World Health Organization: The World Health Report 2001; Mental Health: New Understanding; New Hope. Geneva, World Health Organization 2001

2. VGQ: Rapport annuel du vérificateur général du Québec à l'Assemblée Nationale pour l'année 2002-2003. In Volume Tome ll Québec: Gouvernement du Québec; 2003.

3. WHO/Wonca: Joint report: Integrating mental health into primary care - a global perspective. Geneva: World Health Organization publication data 2008.

4. Henderson C, Phelan M, Loftus L, Dall'Agnola R, Ruggeri M: Comparison of patient satisfaction with community-based vs. hospital psychiatric services. Acta Psychiatr Scand 1999, 99(3):188-195.

5. Jenkins R, Strathdee G: The integration of mental health care with primary care. Int J Law Psychiatry 2000, 23(3-4):277-291.

6. Ruggeri M, Salvi G, Perwanger V, Phelan M, Pellegrini N, Parabiaghi A Satisfaction with community and hospital-based emergency services amongst severely mentally ill service users: a comparison study in South-Verona and South-London. Soc Psychiatry Psychiatr Epidemiol 2006, 41(4):302-309.

7. Thornicroft G, Tansella M: Balancing community-based and hospitalbased mental care. World Psychiatry 2002, 1(2):84-90.

8. Bachrach LR: The state of the State Mental Hospital in 1996. Psychiatr Serv 1996, 47(10):1071-1078.

9. Regier DA, Goldberg D, Burns BJ, Hankin J, Hoeper EW, Nycz GR: Specialist/Generalist division of responsibility for patients with mental disorders. Arch Gen Psychiatry 1982, 39(2):219-224.

10. D'Ercole A, Struening E, Curtis JL, Millman EJ, Morris A: Effects of diagnosis, demographic characteristics, and case management on rehospitalization. Psychiatr Serv 1997, 48(5):682-688

11. Barr W: Characteristics of severely mentally ill patients in and out of contact with community mental health services. J Adv Nurs 2000 31(5):1189-1198.

12. Carr VJ, Lewin TJ, Barnard RE, Walton JM, Allen JL, Constable PM, Chapman $\mathrm{J}$ : Comparisons between schizophrenia patients recruited from Australian general practices and public mental health services. Acta Psychiatr Scand 2002, 105(5):346-355.

13. Kendrick T, Burns T, Freeling P, Sibbald B: Provision of care to general practice patients with disabling long-term illness: a survey in 16 practices. BrJ Gen Pract 1994, 44(384):301-305.

14. Nelson G: Mental Health Policy in Canada. In Canadian Social Policy: Issues and Perspectives Edited by: Westhues A. Waterloo: Wilfrid Laurier University Press; 2006:245-266

15. Geller JL: Treating Revolving-Door Patients Who Have "Hospitalphilia": Compassion, Coercion, and Common Sense. Hosp Community Psychiatry 1993, 44(2):141-146.

16. Ledoux Y, Minner P: Occasional and frequent repeaters in a psychiatric emergency room. Soc Psychiatry Psychiatr Epidemiol 2006, 41(2):115-121.
17. Pasic J, Russo J, Roy-Byrne P: High utilizers of psychiatric emergency services. Psychiatr Serv 2005, 56(6):678-684.

18. Kent $\mathrm{S}$, Fogarty $\mathrm{M}$, Yellowlees $\mathrm{P}: \mathrm{A}$ review of studies of heavy users of psychiatric services. Psychiatr Serv 1995, 46(12):1247-1253.

19. Lang FH, Johnstone EC, Murray GD: Service provision for people with schizophrenia. II. role of general practitioner. Br J Psychiatry 1997, 171:165-168.

20. Nazareth I, King M, Davies S: Care of schizophrenia in general practice: the general practitioner and the patient. Br J Gen Practice 1995, 45(396):343-347.

21. Kushner K, Diamond R, Beasley JW, Mundt M, Plane MB, Robbins K Primary care physisians' experience with mental health consultation. Psychiatr Serv 2001, 52(6):838-840.

22. Brown JB, Lent B, Takhar J, Bishop J: Caring for seriously mentally ill patients. Can Fam Physician 2002, 48(5):915-920.

23. Ziguras SJ, Stuart GW: A Meta-Analysis of the Effectiveness of Mental Health Case Management Over 20 Years. Psychiatr Serv 2000, 51(11):1410-1420

24. Cullen D, Waite A, Oliver N, Carson J, Holloway F: Case management for the mentally ill: a comparative evaluation of client satisfaction. Health Soc Care Community 1997, 5(2):106-115.

25. Björkman T, Hansson L: Case management for individuals with a severe mental illness: a 6 year follow-up study. Int J Soc Psychiatry 2007, 53(1):12-22.

26. Averill PM, Hopko DR, Small DR, Greenlee HB, Varner RV: The role of psychometric data in predicting inpatient mental health service utilization. Psychiatr Q 2001, 72(3):215-235.

27. Fleury MJ: Québec Mental Health Services Networks: Models and Implementation. International J Integr Care 2005, 5:e7.

28. Fleury MJ, Bamvita JM, Tremblay J: Variables associated with general practitioners taking on serious mental disorder patients. BMC Fam Pract 2009, 10:41.

29. Andersen RM: Revisiting the Behavioral Model and Access to Medical Care: Does It Matter? J Health Soc Behav 1995, 36(1):1-10.

30. Lemming MR, Calsyn RJ: Utility of the behavior model in predicting service utilization by individuals suffering from severe mental illness and homelessness. Community Ment Health J 2004, 40(4):347-364.

31. Phelan M, Slade M, Thornicroft G, Dunn G, Holloway F, Wykes T, Strathdee G, Loftus L, McCrone P, Hayward P: The Camberwell Assessment of Need: the validity and reliability of an instrument to assess the needs of people with severe mental illness. Br J Psychiatry 1995, 167(5):589-595

32. Slade M: Assessing the needs of the severely mentally ill: cultural and professional differences. Int J Soc Psychiatry 1996, 42(1):1-9.

33. Slade M, Phelan M, Thornicroft G, Parkman S: The Camberwell Assessment of Need (CAN): comparison of assessments by staff and patients of the needs of the severely mentally ill. Soc Psychiatry Psychiatr Epidemiol 1996, 31(3-4):109.

34. Hansson L, Björkman T, Svensson B: The assessment of needs in psychiatric patients. Interrater reliability of the Swedish version of the Camberwell Assessment of Needs intrument and results from a crosssectional study. Acta Psychiatr Scand 1995, 92(4):285-293.

35. Andresen R, Caputi P, Oades LG: Interrater reliability of the Camberwell Assessment of Need Short Appraisal schedule. Aust NZJ Psychiatry 2000, 34(5):856-861.

36. Arvidsson $\mathrm{H}$ : Test-retest reliability of the Camberwell Assessment of Need (CAN). Nord J Psychiatry 2003, 57(4):279-283.

37. McCrone $P$, Leese $M$, Thornicroft $G$, Schene A, Knudsen HC, VàzquezBarquero JL, Tansella M, Becker T: A comparison of needs of patients with schizophrenia in five European countries: the EPSILON Study. Acta Psychiatr Scand 2001, 103(5):370-379.

38. Yeh HS, Luh RL, Liu HJ, Lee YC, Slade M: Reliability of the Camberwell assessment of need (Chinese version) for patients with schizophrenia at a daycare center of Taiwan. Soc Psychiatry Psychiatr Epidemiol 2006, 41(1):75-80.

39. Bonsack C, Lesage A: Deux instruments pour évaluer les besoins de soins de santé mentale: une étude comparative chez des personnes longuement hospitalisées. Ann Med Psychol (Paris) 1998, 156(4):244-257.

40. Vasiliadis HM, Lesage A, Adair C, Boyer R: Service use for mental health raisons: Cross-provincial difference in rates, determinants, and equity of acces. Can J Psychiatry 2005, 50(10):614-619. 
41. Ministère de la Santé et des Services sociaux (MSSS): Plan d'action en santé mentale 2005-2010. La force des liens. Québec 2005.

42. MSSS: MED-ECHO, banque de données des hospitalisations du Ministère de la santé et des services sociaux du Québec. Québec: Gouvernement du Québec; 2004.

43. Carr VJ, Johnston PJ, Lewin TJ, Rajkumar S, Carter GL, Issakidis C: Patterns of service use among persons with schizophrenia and other psychotic disorders. Psychiatr Serv 2003, 54(2):226-235

44. Narrow WE, Regier DA, Norquist G, Rae DS, Kennedy C, Arons B: Mental health service use by Americans with severe mental illness. Soc Psychiatry Psychiatr Epidemio/ 2000, 35(4):147-155.

45. Bijl RV, Ravelli A: Psychiatric Morbidity, Service Use, and Need for Care in the General Population: Results of the Netherlands Mental Health Survey and Incidence Study. Am J Public Health 2000, 90(4):602-607.

46. Lefebvre J, Lesage A, Cyr M, Toupin J, Fournier L: Factors Related to Utilization of Services for Mental Health Reasons in Montreal, Canada. Soc Psychiatry Psychiatr Epidemiol 1998, 33(6):291-298.

47. Lin E, Goering PN, Lesage A, Streiner DL: Epidemiologic Assessment of Overmet Need in Mental Health Care. Soc Psychiatry Psychiatr Epidemiol 1997, 32(6):355-362.

48. Gupta S, Black DW, Arndt S, Hubbard WC, Andreasen NC: Factors associated with suicide attempts among patients with schizophrenia. Psychiatr Serv 1998, 49(10):1353-1355.

49. Siris SG: Suicide and schizophrenia. J Psychopharmacol 2001, 15(2):127-135.

50. Harkavy-Friedman JM, Restifo K, Malaspina D, Kaufman CA, Amador SF Yale SA, Gorman JM: Suicidal behavior in schizophrenia: characteristics of individuals who had and had not attempted suicide. Am J Psychiatry 1999, 156(8):1276-1278

51. Pirkis JE, Burgess PM, Meadows GN, Dunt DR: Suicidal ideation and suicide attempts as predictors of mental health service use. Med J Aust 2001, 175(10):542-545.

52. Gallagher J, Teesson M: Measuring disability, need and outcome in Australian community mental health services. Aust NZ J Psychiatry 2000, 34(5):850-855

53. Leese M, Johnson S, Slade M, Parkman S, Kelly F, Phelan M, Thornicroft G: User perspective on needs and satisfaction with mental health services. PRiSM Psychosis Study. 8. Br J Psychiatry 1998, 173:409-415.

54. Slade M, Leese M, Cahill S, Thornicroft G, Kuipers E: Patient-rated mental health needs and quality of life improvement. BrJ Psychiatry 2005, 187:256-261.

55. Albert M, Becker T, McCrone P, Thornicroft G: Social networks and mental health service utilisation. A literature review. Int J Soc Psychiatry 1998, 44(4):248-266

56. Fleury MJ, Grenier G, Caron J, Lesage A: Patient's report of help provided by relatives and services to meet their needs. Community Ment Health J 2008, 44(4):271-281.

57. Arvidsson $\mathrm{H}$ : The development of needs in a group of severely mentally ill. A 10-year follow-up study after the 1995 Swedish mental health care reform. Soc Psychiatry Psychiatr Epidemiol 2008, 43(9):705-713.

58. Barbeau D, Perron S, Ouellet V, Morency P: Un regard critique sur les services de consultation sans rendez-vous. Le médecin du Québec 2001, 36(1):71-75

59. Fleury MJ, Bamvita JM, Farand L, Tremblay J: Variables associated with general practitioners taking on patients with common mental disorders. Ment Health Fam Med 2009, 5(3):149-160.

60. Adair CE, MCDougall GM, Mitton CR, Joyce AS, Wild TC, Costigan N, Kowalsky L, Pasmeny G, Beckie A: Continuity of care and health outcomes among persons with severe mental illness. Psychiatr Serv 2005, 56(9):1061-1069.

61. Henrickx HA, Kinney F, Clarke GN, Paulson RI: Assertive Community Treatment Versus Usual Care in Engaging and Retaining Clients With Severe Mental Illness. Psychiatr Serv 1997, 18(10):1297-1306.

62. Adair CE, McDougall GM, Beckie A, Joyce A, Mitton C, Wild CT, Gordon A Costigan N: History and Measurement of Continuity of Care in Mental Health Services and Evidence of its Role in Outcomes. Psychiatr Serv 2003, 54(10):1351-1356.

63. Thornicroft $G$, Bebbington P, Leff J: Outcomes for long-term patients one year after discharge from a psychiatric hospital. Psychiatr Serv 2005, 56(11):1416-1422.

64. Kanter J: Clinical Case Management: Definition, Principales, Components. Hosp Community Psychiatry 1989, 40(4):361-368.
65. Walters P, A T, Goldberg D: Psychiatry in Primary Care. In Essential Psychiatry Edited by: Murray RM, Kendler KS, McGuffin P, Wessely S, DJ. C: Cambridge Medicine; 2008:479-497.

66. Ücok A, Soygür H, Atakli C, Kuscu K, Sartorius N, Duman ZC, Polat A, Erroc $\mathrm{S}$ : The impact of antistigma education on the attitudes of general practitioners regarding schizophrenia. Psychiatry Clin Neurosci 2006, 60(4):439-443.

67. Schoen C, Osborn R, Huynh PT, Doty M, Peugh J, Zapert K: On the front lines of care: primary care doctors' office systems, experiences, and view in seven countries. Health Aff (Millwood) 2006, 25(6):w-555-w571.

68. Craven M, Bland R: Better practices in collaborative mental health care; an analysis of the evidence base. Can J Psychiatry 2006, 51(6 Suppl 1):7s-72s.

69. Parslow RA, Jorm AF: Who uses mental health services in Australia? An analysis of data from the National Survey of Mental Health and Wellbeing. Aust N Z J Psychiatry 2000, 34(6):997-1008.

70. Sullivan G, Jackson CA, Spritzer KL: Characteristics and service use of seriously mentally ill persons living in rural areas. Psychiatr Serv 1996, 47(1):57-61

\section{Pre-publication history}

The pre-publication history for this paper can be accessed here: http://www.biomedcentral.com/1472-6963/10/141/prepub

doi: $10.1186 / 1472-6963-10-141$

Cite this article as: Fleury et al., Professional Service Utilisation among Patients with Severe Mental Disorders BMC Health Services Research 2010, $10: 14$

\section{Submit your next manuscript to BioMed Centra and take full advantage of:}

- Convenient online submission

- Thorough peer review

- No space constraints or color figure charges

- Immediate publication on acceptance

- Inclusion in PubMed, CAS, Scopus and Google Scholar

- Research which is freely available for redistribution 